\title{
Liquid/solid phase extraction of water samples used for toxicity testing in the German Bight
}

\author{
J.-C. Bening, L. Karbe, G. Schupfner \\ Universität Hamburg, Institut für Hydrobiologie und Fischereiwissenschaft, Zeiseweg 9, W-2000 Hamburg 50, Germany
}

\begin{abstract}
During the Bremerhaven Workshop, a liquid-solid enrichment technique was used to extract lipophilic organic compounds from seawater. The toxicity of extracts was tested after dilution with seawater corresponding to different enrichment factors. Using a hydroid bioassay, extracts from the more inshore areas proved significantly more toxic compared to those from the more offshore locations. Methodological aspects of this type of toxicity testing are discussed.
\end{abstract}

\section{INTRODUCTION}

There are thousands of unidentified organic compounds at concentrations below present detection limit dissolved in seawater, and therefore enrichment techniques have been developed to make them amenable to current analytical technology (Ehrhardt et al. 1991). Since Richard \& Fritz (1973), Osterroth (1974) and Junk et al. (1976) established macromolecular resins for the extraction of trace organic contaminants in water, such resins have been commonly used for both chemical and biological research. Thus, Yamasaki \& Ames (1977) described the quantitative isolation of mutagenic substances from human urine and Kool et al. (1982) reviewed the use of water concentrates for an assessment of drinking water quality. For limnological purposes, Sloof \& De Zwaart (1983) suggested that the liquid-solid extraction method should be applied as a routine procedure in monitoring of surface water.

Not only the preparation of organic water concentrates but also their use in biotests has become an essential part of detecting potential toxicity in freshwater ecosystems (Dutka et al. 1981, Moretton et al. 1991). In the marine environment Stebbing (1979) used liquidsolid extraction techniques with a hydroid bioassay to demonstrate biologically detectable metal contamination offshore. In the work presented here, we describe a modified extraction method for organic contaminants for use in marine environments and report our results on testing the eluates for toxicity in a hydroid bioassay.

\section{MATERIAL AND METHODS}

As a sorbent for the extraction of North Sea water, polystyrene cross-linked by divinylbenzene was used. These resins adsorb lipophilic organic substances to varying degrees depending on structure (Green \& Kowalski 1984) and are available under the trade name Amberlite XAD (Rohm and Haas Co.). Two different types (XAD 2 and 4) were mixed in a 1:1 ratio and prepared as follows:

The research grade resins were cleaned up to nanograde quality using a modified Soxhlet extraction under utilization of an extractor similar to that described by Ehrhardt (1987). Prior to extraction, the resin mixture was slurried into brown glass columns $(30 \times 3.5 \mathrm{~cm}$ diam., volume $210 \mathrm{ml})$. Acetone followed by acetonitrile (Merck Uvasol) containing $10 \%(\mathrm{v} / \mathrm{v})$ water was used for extraction. The solvents were changed every $12 \mathrm{~h}$; the clean-up procedure was finished after $48 \mathrm{~h}$. The efficiency of the procedure was checked by GC-ECD. The columns were then stored under $10 \%$-methanol-water for max. $14 \mathrm{~d}$ in a refrigerator. 


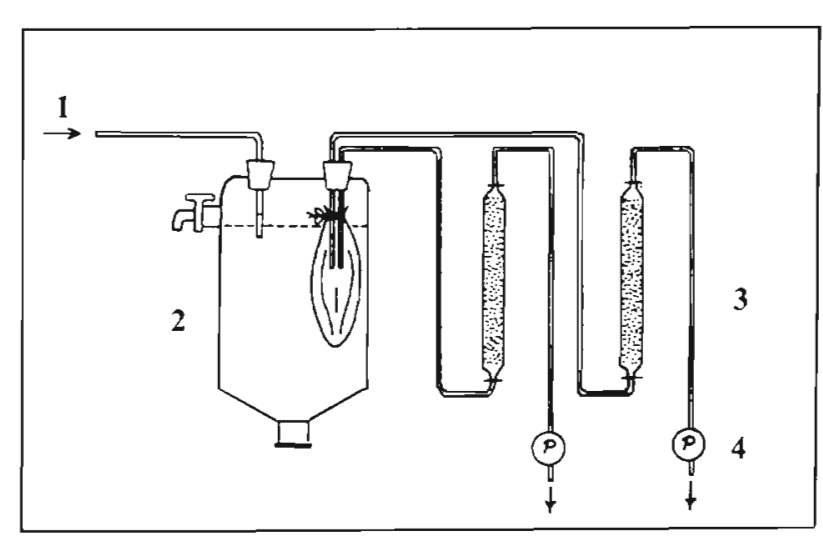

Fig. 1. Scheme of the sampling apparatus. (1) PTFE tube system from the lance, (2) sedimentation flask with $100 \mu \mathrm{m}$ plankton gauze, (3) XAD column(s), (4) tube pump(s). Arrows show the direction of water flow

Samples were taken on board RV 'Vaidivia' using a pre-installed PTFE tube system in a probe extending about $1.5 \mathrm{~m}$ beneath the hull, its muzzle in the direction of the ship's motion (Fig. 1; Bening \& Karbe 1992). During sampling, the speed was between 1 and 10 knots and the flow rate was $350 \mathrm{ml} \mathrm{min}^{-1}$. The total amount of extracted water was $250 \mathrm{l}$ for each column. Charged columns were stored in a refrigerator and extracted immediately after the cruise using $500 \mathrm{ml}$ acetone in the modified Soxhlet extractor. Acetone was removed by distillation and rotary evaporation under reduced pressure. The final aqueous extracts had a volume of about $100 \mathrm{ml}$ and contained 1 to $2 \%$ acetone ( $\mathrm{v} / \mathrm{v}$, measured by UV-VIS spectrophotometry).

To test the extracts, a semistatic hydroid bioassay using the marine species Eirene viridula was used (Karbe et al. 1984). To enable a first calculation it was assumed that the enrichment factor of the extracts has a constant relationship to the total amount of extracted water and was therefore 2500 . As the original extracts were lethal, enrichment factors of 150,300 and 600 were prepared by dilution with artificial seawater.

As a test criterion, the asexual reproduction rate $(K)$ of the hydroid colonies was determined over a period of $10 \mathrm{~d}$. The number of replicates was 5 or 8 for each test series and concentration. Summary statistics were calculated using a STATGRAPHICS programme; the significance levels were evaluated by the KolmogorovSmirnov Two-Sample-Test $(\alpha=0.05)$.

\section{RESULTS}

Due to limited shiptime during the first cruise (March 16 to 20, 1990) it was impossible to sample more than $12 \mathrm{~h}$ at each station. Therefore, the steaming time between Stns $1 \& 4,4 \& 6,6 \& 8$ as well as around
9 was utilized to sample a sufficient amount of water for extraction. The results are given in Fig. 2 .

It is clear that there is a distinct concentrationresponse relationship for the 3 different extract concentrations from each region. It can also be seen that the reproduction rate $(K)$ is lower for the extracts obtained from nearshore waters (Stns 1 to 6 ), relative to those more offshore. In detail, there are significant differences ( $5 \%$ level) between the controls and extracts with an enrichment factor of 600 (exception Stns 6 to 8 ). For the diluted extract with an enrichment factor of 300 , there is a significant difference only for the 2 nearshore areas, and the 150-fold natural concentration does not differ significantly from the pooled controls for all 4 parts of the transect sampled.

During the second cruise (March 21 to 29) there was enough shiptime to sample water by continuous pumping over the whole time. For this purpose, the ship was held bow on to the iocal current. Adsorption columns were used on Stns 1, 5, $7 \& 9$. The results are given in Fig. 3

Generally, results were similar to those from the first cruise in that nearshore extracts seem to be more toxic than those taken offshore. As in the previous experiment, the eluates diluted to an enrichment factor of 150 did not show any results which could be safely assumed to differ from the controls. Those extracts which have been tested using an enrichment factor of 300 caused a more obvious toxic response. A clear reduction of reproduction ( $K=20 \%$ of the pooled controls)

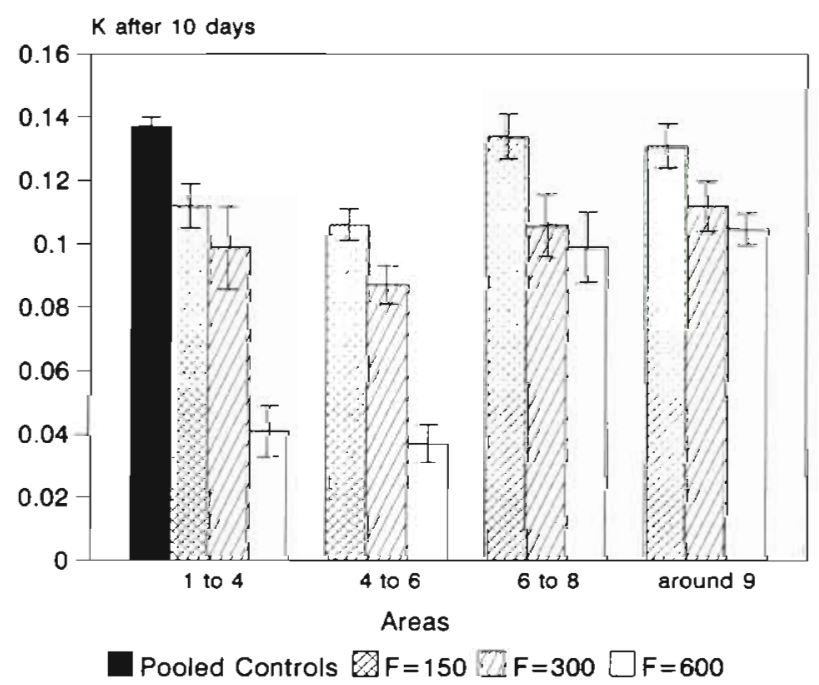

Fig. 2. Eirene viridula. Reproduction rate of colonies in XAD extracts of water from the areas between Stns $1 \& 4,4 \& 6,6 \&$ 8 and around 9 . Bar graphs show the reproduction rate $(K)$ and standard errors under different enrichment factors of extracts $(F)$ over a test period of $10 \mathrm{~d}$. Number of replicates for each test series $=8$ 


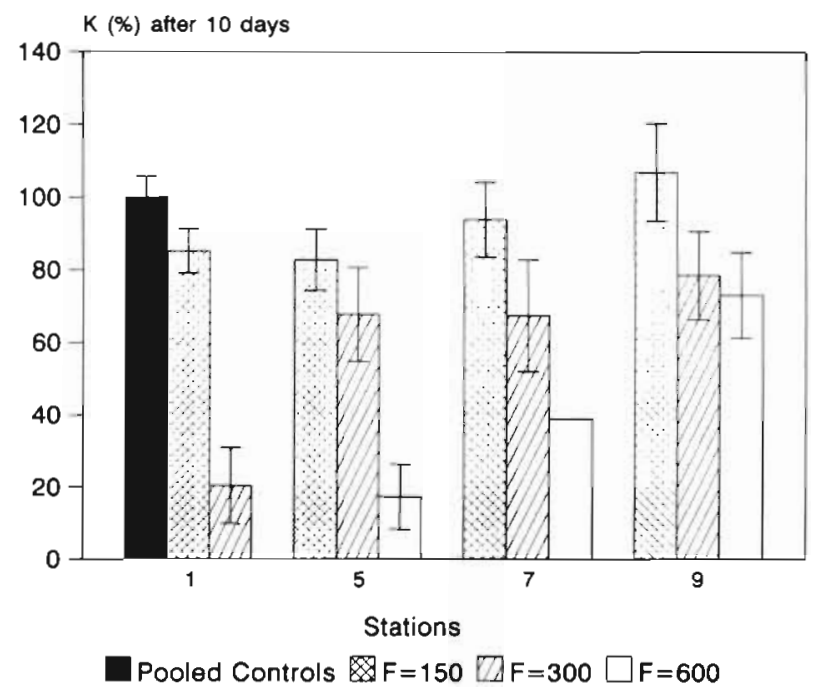

Fig. 3. Eirene viridula. Reproduction rate of colonies in XAD extracts of water retrieved around Stns $1,5,7 \& 9$. Reproduction rate $(K)$ and standard errors are expressed as percent of the pooled controls. Number of replicates $=5$

was detected, especially for Stn 1. The most marked differences were obtained using the enrichment factor of 600 . The range of toxic responses was from lethal (Stn 1) to a $K$-value of $73 \%$ of the controls (Stn 9); the differences between Stns 1-5 compared to 7-9 are statistically significant.

\section{DISCUSSION}

Green et al. (1986) described the suitability of XAD for a time-integrated measurement of the concentrations of bioavailable compounds in seawater. Our intention was to describe the sublethal toxicity of extracted and concentrated organic compounds from water samples taken on the German Bight transect. However, we could not attribute the major causes for the observed toxic effects either to a specific substance or a physiological mechanism. For toxicological purposes it is important to consider that any extraction method automatically involves a manipulation of the original medium to be examined. Therefore, its use can only be justified if there is little or no chance to describe the toxic potential with the help of in situ biotests (Bening \& Karbe 1992). An environmental approach in aquatic toxicology must take possible synergistic or antagonistic effects into consideration, so it is environmentally unrealistic to assess effects of a single substance in isolation.

Depending on the degree of contamination, it is important to tune the concentration factor of the eluate according to the sensitivity of the bioassay applied. Furthermore, the toxicity of the extraction solvent must be taken into consideration. Liquid-solid method is therefore preferable to liquid-liquid extraction.

The main risks of the method described above are that different trace compounds may be adsorbed with different efficiencies (van Rossum \& Webb 1978), artefacts may be produced during extraction and distillation, and small quantities of the extraction solvent could remain in the final extract. The different adsorption efficiencies depend on the type of sorbent, but the other 2 risks can be minimized using acetone (Stratton 1986, Ehrhardt et al. 1991). In any case it is imperative to operate with inert materials (PTFE, quartz glass, no PVC) and solvents of nanograde quality. Blanks must be checked for purity and the work-up procedure has to be carried out in the same way for each column.

The charged columns seem to be relatively stable (Green \& Le Pape 1987), but the final extract should be stored in a freezer below $-20^{\circ} \mathrm{C}$ and tested as soon as possible. Residual acetone can be measured by UVVIS spectrophotometry; its content must be adjusted to the same value in the dilution series and in the controls. In recent years, liquid carbon dioxide has been reported as an extraction medium (King 1989). We assume that this may be an appropriate way to overcome some of the difficulties with other solvents.

Acknowledgement. The authors thank Dr Manfred Ehrhardt (IfM, Kiel) for reading the manuscript.

\section{LITERATURE CITED}

Bening, J.-C., Karbe, L. (1992). Toxisches Potential von Meerwasserkonzentraten aus der Nordsee und der Irischen See. Ber. Zentr. Meeres- u. Klimaforsch. Hamburg 24: $25-29$

Dutka, B. J., Jova, A., Brechin, J. (1981). Evaluation of four concentration/extraction procedures on waters and effluents collected for use with the Salmonella typhimurium screening procedure for mutagens. Bull. environ. Contam. Toxicol. 27.758-764

Ehrhardt, M. (1987). Lipophilic organic material: an apparatus for extracting solids used for their concentration from sea water. ICES Techn. Mar. Environ. Sci. 4: $14 \mathrm{pp}$

Ehrhardt, M., Klungsøyr, J., Law, R. J (1991). Hydrocarbons: review of methods for analysis in sea water, biota, and sediments. ICES Techn. Mar. Environ. Sci. 12: 47 pp

Green, D. R., Kowalski, D. (1984). Amberlite XAD-2 resin columns: documentation of their performance in the extraction of organics from water. Available from Seastar Instruments Ltd., 2045 Mills Road, Sidney, British Columbia, Canada V8L 351

Green, D. R., Le Pape, D. (1987). Stability of hydrocarbon samples on solid-phase extraction columns. Anal. Chem. 59: 699-703

Green, D. R., Stull, J. K., Heesen, T C. (1986). Determination of chlorinated hydrocarbons in coastal waters using a moored in situ sampler and transplanted live mussels. Mar. Pollut. Bull. 17: 324-329 
Junk, G. A., Chriswell, C. D., Chang, R. C., Kissinger, L. D., Richard, J. J., Fritz, J. S., Svec, H. J. (1976). Applications of resins for extracting organic components from water. $Z$. Anal. Chem. 282: 331-337

Karbe, L., Borchart, T., Dannenberg, R., Meyer, E. (1984). Ten years of experience using marine and freshwater hydroid bioassays. In: Persoone, G. et al. (eds.) Ecotoxicological testing for the marine environment, Vol. II. State University, Ghent, p. 99-129

King, J. W. (1989). Fundamentals and applications of supercritical fluid extraction in chromatographic science. J. Chromatogr. Sci. 27: 355-364

Kool, H. J., van Kreijl, C. F., Zoeteman, B. C. J. (1982). Toxicology assessment of organic compounds in drinking water. CRC Crit. Rev. Environ. Contr. 12(4): 307-357

Moretton, J., Baro, P., Zelazny, A., D'Aquino, M. (1991). Polluted water concentrates: induction of genetic alterations in Saccharomyces cerevisiae D7 strain. Bull. environ. Contam. Toxicol. 46: 203-207

Osterroht, C. (1974). Development of a method for the extraction and determination of non-polar, dissolved organic substances in sea water. J. Chromatogr, 101: $289-298$

Richard, J. J., Fritz., J. S. (1973). Adsorption of chlorinated pesticides from river water with XAD-2 resin. Talanta 21: 91-98

van Rossum, P., Webb, R. G. (1978). Isolation of organic water pollutants by XAD resins and carbon. J. Chromatogr. 150: 381-392

Slooff, W., de Zwaart, D. (1983). Bio-indicators and chemical pollution of surface waters. Environ. Monitoring Assess. 3: $237-245$

Stebbing, A. R. D. (1979) An experimental approach to the determination of biological water quality. Phil. Trans. R. Soc. Lond. B 286: 465-481

Stratton, G. W. (1986). Medium composition and its influence on solvent-pesticide interactions in laboratory bioassays. Bull. environ. Contam. Toxicol. 36: 807-814

Yamasaki, E., Ames, B. N. (1977). Concentration of mutagens from urine by adsorption with the non-polar resin XAD-2: cigarette smokers have mutagenic urine. Proc. natl Acad. Sci. U.S.A. 74: 3555 